\title{
A REVIEW ON THE PERFORMANCE OF THE NANOFLUID BASED SOLAR COLLECTORS - SOLAR ENERGY
}

\begin{tabular}{|l|l|l|l|l|}
\hline Kapil Sharma & Satnam Singh & Manvendra Yadav & Sanjay Yadav & Naveen Mani \\
School of Mechanical & School of Mechanical & Department of & Department of & Tripathi \\
Engineering, Lovely & Engineering, Lovely & Mechanical & Mechanical & Department of \\
Professional & Professional & Engineering, ITS & Engineering, ITS & Mechanical \\
University, Phagwara, & University, Phagwara, & Engineering College, & Engineering College, & Engineering, Ben- \\
Punjab & Greater Noida & Greater Noida & Gurion University of \\
& & & & Negev, Beer-Sheva, \\
& & & & Israel \\
\hline
\end{tabular}

\begin{abstract}
Using nanofluids as an innovative kind of liquid blend with a trivial volume fraction (in percent) of nanometer-sized solid particles in suspension is a fairly a novel arena or idea. The objective of this presented review paper is to inspect the performance of the nanofluid-based solar collector (NBSC). In past few years for a number of experimental and industrial thermal engineering systems solar energy has proven to be the best input energy source. The scarcity of fossil fuels and environmental contemplations motivated the researchers to utilize alternative energy sources such as solar energy, wind energy, tidal energy etc. Therefore, it is essential to boost the performance of the solar thermal engineering systems. Because of better rheological properties nanofluids are utilized to build up the performance of conventional solar thermal engineering systems. Therefore, major part of this presented review paper lays a main emphasis to investigate the effects of nanofluids on the performance of solar collectors. Some proposals are also given to use the nanofluids for future work in different solar thermal engineering systems such as parabolic trough systems (PTS), solar thermoelectric cells and finally, the challenges of using nanofluids in solar energy devices are reviewed in brief.
\end{abstract}

Keywords: Solar energy, solar thermal systems, nanofluids, solar thermometric cells, parabolic trough system, solar collector.

\section{INTRODUCTION}

In recent years, a tremendous growth in the energy sector especially in the field of solar energy is observed due to increased scientific developments. Several developments and examinations were carried out in the area of solar energy. Scientific developments have been carried out in the area of concentrated solar power (CSP). Solar collectors converts the solar radiation into heat and then transfer this heat to a medium i.e. heat transfer fluid (HTF). The solar energy is used to carry out the heating or cooling processes [1]. Generation of Sustainable energy is identified as the most important challenge faced by our society today. The demand of electricity consumption is increased day by day and the production of electricity has become a key issue in the industry. Electricity adds a main segment to the world's total energy demand and is growing faster than liquid fuels, natural gas, and coal, petroleum and natural gas which are used to produce steam in boilers of power plants and these power plants stand a majority load in the electricity power plant in the whole world. The heat exchangers that are used to transform the solar radiation energy to internal energy of the transport medium are known as solar thermal collectors. Non-concentrating solar 
collectors can be used if an excessive amount of solar radiation is concentrated on a fairly lesser collecting area [2]. Over the past $10-15$ years concentrated solar energy has become the input for an increasing number of experimental and commercial thermal systems [3]. For solar collectors the utilization of nanofluids as a working fluid is a relatively a novel idea. Various researchers are interested to develop the various aspects of solar energy because of it is readily available in nature [2].

In direction to upsurge the effectiveness or performance of solar collectors, one of the most appropriate method is to change the working fluid like water, ethylene glycol by higher thermal conductivity fluids like aluminum oxide, copper oxide. The blend of base fluids like water or ethylene glycol with suitable nanoparticles like silicon oxide or aluminium oxide are called nanofluids. In comparison with conventional heat transfer fluids nanofluids exhibits exceptional heat transfer properties [1].Common type of base fluids such as water, ethylene glycol, therminol VP-1 and heat transfer oil plays a vital role in several industrial processes such as power generation, heating or cooling processes, chemical processes, and microelectronics. However, the above mentioned base fluids exhibits low heat transfer properties and thus cannot reach high level of heat exchange rates in thermal engineering devices. A way to solve this problem is to use ultra-fine powdered nanoparticles as mentioned suspended in common fluids like water or ethylene glycol to increase their thermal conductivity. The suspension of powdered form nano-sized particles (metallic or non-metallic oxides) ranging from 1 to $100 \mathrm{~nm}$ in a conventional base fluid as discussed above is known as a nanofluid [4]. Therefore, we can say that the nanofluids are the suspensions of metallic or nonmetallic nanoparticles in a base fluid like water or ethyl alcohol [5]. Nanofluids exhibits better stability, rheological properties, and considerably higher thermal conductivities. In recent years both experimental and theoretical work was done by various scientists or researchers to examine the effects of nanofluids on the enhancement of heat transfer in thermal engineering devices, [3]. The remarkable features of nanofluids are increase in liquid thermal conductivity, liquid viscosity, and heat transfer coefficient.

\section{EXPERIMENTAL INVESTIGATIONS}

Tyagi et al. [6] worked on theoretical and numerical observations to study the effects of different criterion that is nanoparticle size, volume fraction, collector geometry on the efficiency of a low-temperature nanofluid based direct absorption solar collector (DASC).In this paper water based aluminum nanoparticles $\mathrm{Al}_{2} \mathrm{O}_{3}$ taken as a working fluid (i.e. composition of water and aluminum nanoparticles). Numerical modelling of DASC was also done by using two dimensional heat transfer analysis. The variation of collector efficiency as a function of the particle volume fraction $(0.1 \%$ to $5 \%$ ), particle size, collector geometry was studied experimentally. The variation of collector efficiency as a function of the particle volume fraction (\%), where the volume fraction varies from $0.1 \%$ to $5 \%$ shown in Figure1.The results revealed that by the inclusion of nanoparticles in the working fluid, the efficiency increases remarkably for low values of volume fraction of nanoparticles However, it was found that the inclusion of more nanoparticles is not beneficial because the efficiency remains approximately constant 
for a volume fraction higher than $2 \%$. Investigations were also carried out regarding the effects of nanoparticles size and collector geometry on the collector efficiency. The results also revealed that the efficiency increases slightly with an increase in the size of nanoparticles. The collector efficiency increases as the collector's height increases and reaches up to the value of 80 $\%$, and with the length factor the efficiency firstly increases with length and then gradually falloffs. It was observed that the rise of collector efficiency to the rise in attenuation of sunlight passing through the collector due to the nanoparticles inclusion leads to the increase of collector efficiency. On comparison, the DASC using nanofluid as a working fluid have $10 \%$ efficiency higher than that of the conventional flat plate collector using water as a working fluid. The results revealed that the efficiency increases slightly with an increase in the size of nanoparticles. (Figure 2).

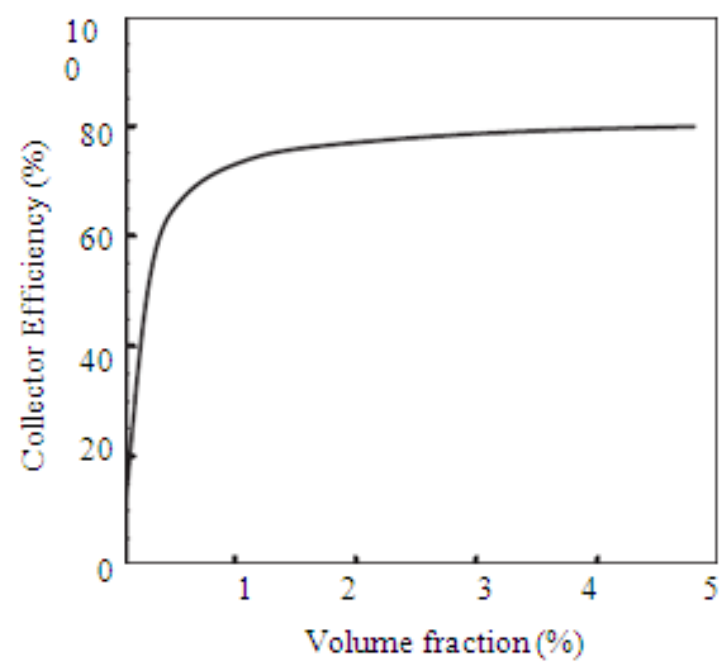

Fig.1 Effect of particle volume fraction on collector efficiency [6]

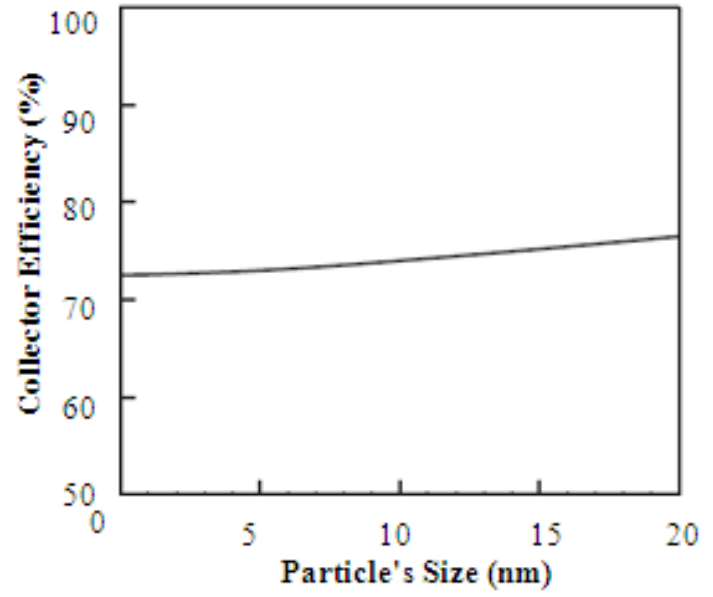

Fig.2 Effect of nanoparticles size on collector efficiency [6]

Otanicar et al. [7] carried out an experimental and theoretical investigations to study the effects of different nanofluids such as carbon nanotubes, graphite, and silver on the performance of a direct absorption solar collector (DASC). The investigations were carried out to check the variation of collector efficiency as a function of volume fraction for different nanomaterials mentioned above. The DASC data are compared with the conventional collector configuration where the solar energy is absorbed on a black plate surface. It was concluded that by the inclusion of small amounts of nanoparticles leads to the remarkable improvement of the collector efficiency. The efficiency increases up to approximately $0.5 \%$ of volume fraction. After a volume fraction of $0.5 \%$, the efficiency begins to level off and even fall slightly with increasing volume fraction. 
ELK

Asia Pacific Journals

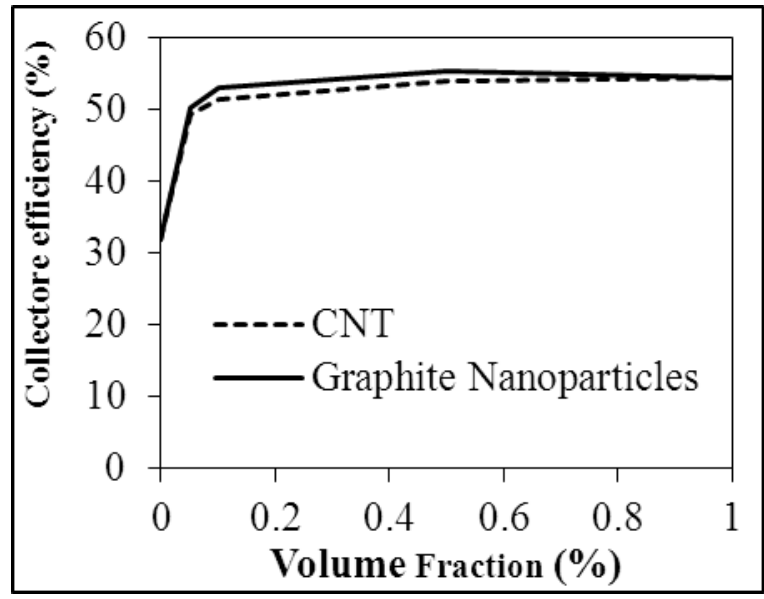

Figure 3: Variation of collector's efficiency with volume fraction [7]

By using graphite nanoparticles of size 30 $\mathrm{nm}$, the performance of DASC over a conventional flat surface absorber was increased up to $3 \%$ which was considered to be the maximum enhancement in its performance. In case of silver particles, the main difference in the steady-state efficiency between nanofluids occurred when the size of these particles is between 20 and $40 \mathrm{~nm}$. It was found that when the size of silver nanoparticles reduces from 40 $\mathrm{nm}$ to $20 \mathrm{~nm}$ efficiency enhancement of $6 \%$ was observed. The collector efficiency as a function of volume fraction was plotted for silver graphite and CNT nanoparticles in figure 3. It was seen that as the size of nanoparticles increases, the collector efficiency decreases.

Taylor et al. [8] carried out theoretical \& experimental investigations regarding the applicability of nanofluids in high flux solar collectors and to compare the performance of nanofluid-based concentrating solar thermal system with a conventional system. The results indicated that the usage of a nanofluid as the working fluid in the receiver enhance the efficiency by $10 \%$. It was seen that Collector efficiency enhancement of $5 \%-10 \%$ is possible with a
ELK Asia Pacific Journals - Special Issue

ISBN: 978-81-930411-4-7

nanofluid used as the working fluid in the receiver. It was concluded that using graphite/therminol VP-1 nanofluid for 10100 MWe power plants, with volume fractions approximately up to $0.001 \%$ or less could be advantageous. The authors estimated that in a solar resource like Tucson, Arizona combining solar thermal power tower with a nanofluid receiver with the capacity of $100 \mathrm{MWe}$ operating, could generate $\$ 3.5$ million more per year. It was observed that, nanofluids are not expected to be appropriate for using as the working fluid for parabolic dish or trough solar thermal systems, but further optimization or cost reductions might increase their range of applicability.

Taylor et al. [9] carried out theoretical and experimental investigations to study the optical property characterization of various nanoparticles such as graphite, silver, copper, gold, and aluminum suspended in water and therminol-VP1 as the base fluids to determine their potential to be utilized in direct absorption solar collectors (DASC). To determine the optical property of nanofluids like graphite, aluminum measurement and modelling techniques were used. For several concentrations of aqueous graphite nanofluids extinction coefficients were studied by using modelling and experimental methods. The results showed that approximately $95 \%$ of incoming sunlight coming from the sun can be absorbed by a nanofluid having thickness greater than equal to $10 \mathrm{~cm}$ with very small nanoparticle volume fractions (less than 0.00001 or $10 \mathrm{ppm}$ ). Thus, nanofluids could be utilized to absorb sunlight with a small amount of viscosity and/or density. It was concluded that absorption is generally due to the nanoparticles at shorter wavelengths and due to the base fluids at longer wavelengths. 
Natarajan \& Sathish [10] carried out an investigation to study the role of nanofluids in solar water heater. The objective of this study was to examine and compare the heat transfer properties of the nanofluids with the conventional fluids. During this investigation water based Multiwall carbon nanotubes (MWCNTs) were used as nanofluids with volume fraction in percent taken as 0.2, 0.4, 0.6, 0.8, 1.0, and 1.2. For the preparation of CNTs sodium dodecyl sulphate (SDS) was used as a surfactant. Sodium dodecyl sulphate was used to obtain stable nanofluids. It was found that for the stable CNT dispersion SDS surfactant proves to be a suitable dispersant. Transient hot-wire method was used to measure the thermal conductivities of nanofluids. It was concluded that the thermal conductivity of water-based MWCNT nanofluid increases as a function of volume fraction of MWCNTs. At a volume fraction of $1.0 \%$ the thermal conductivity of nanofluid increased up to $41 \%$. The comparison between the experimental data for MWCNT in deionized water was done and the values were calculated from Hamilton-Crosser model. It was concluded that the measured values of thermal conductivity is greater than those calculated from Hamilton-Crosser model (HDC). It was also concluded that if nanofluids are used as a heat transport medium, it increases the efficiency of the traditional solar water heater.

Khullar et al. [11] carried out theoretical \& numerical investigation regarding the application of nanaofluids as the working fluid in concentrating parabolic solar collectors. In this paper mathematical modelling of heat transfer and flow aspects of the linear parabolic solar collectors had been done. Al-water based nanofluid was used as the working fluid and to solve the equations numerically FDM (finite difference method) technique has been used. Evaluation and comparison of the two dimensional temperature field, optical and thermal efficiencies, and mean-outlet temperatures had been done for both conventional parabolic collectors utilizing water as a working fluid and nanofluid based collectors using nanofluid as a working fluid. In order to achieve the desired output temperature the effect of various operating criterion such as concentration ratio, receiver length, fluid velocity, volume fraction of nanoparticles taken into consideration. The results indicated that in terms of thermal and optical efficiencies and higher outlet temperatures under same working conditions the collector using nanofluid as a working fluid has a better performance as compare to the conventional collector. The results also showed that the inclusion of aluminium nanoparticles into the base fluid (water) significantly improves its absorption characteristics.

Sani et al. [12] carried out an investigation about the optical and thermal properties of nanofluids as a function of the nanoparticle concentration consisting in aqueous suspensions of single wall carbon nanohorns (SWCNH). The characteristics of these nanofluids were evaluated in view of their use as sunlight absorber fluids in a solar device, hence characterization of SWCNH was done in aqueous suspensions as new nanofluids for the utilization in the field of solar energy. It was found that the thermal conductivity of the nanofluids was higher than the water used as the operating fluid. According to spectral transmission measurement SWCNHs play an important role in improving the photonic properties of 
the fluid, leading to a major increase of the light extinction level even at very low concentrations. At the investigated concentrations up to $10 \%$ rise in the thermal conductivity was observed. For the optimization of heat transfer efficiency, optical and thermal properties of the nanofluid provides valuable information to the sunlight collector designer. It was concluded that for efficiency enhancement the usage of SWCNH water nanofluid as absorber in solar devices appears a very promising step.

Sani et al. [13] carried out an experimental investigation to study the potential of carbon nanohorn (CNH)-based suspensions for solar thermal collectors. In this paper the optical characterization of new fluid made up of single-wall carbon nanohorns (SWCNH) and ethylene glycol as a base fluid for solar energy applications were studied. In optical characterization to measure the potential of SWCNH-glycol suspension as direct sunlight absorbers, the optical properties of the nanofluid were examined as a function of the nanoparticle concentration. The measured spectral transmission showed that SWCNHs play an important role to enhance the photonic properties of the fluid, leads to a remarkable growth of the light extinction level even at very small concentrations. To evaluate the differences between SWCNHs and conventional commercial carbon forms, i.e. Carbon-black particles the obtained results had been compared with glycol-based amorphous carbon suspensions It was found that Carbon nanohorn $(\mathrm{CNH})$ plays an vital role to increase the sunlight absorption with respect to the pure base fluid \& SWCNHs spectral features are far more favourable than those of amorphous carbon-black particles for the specific application. It was concluded that, the use of SWCNH-glycol based nanofluid as direct absorber or working fluid in solar devices can be beneficial for increasing the collector efficiency and compactness of thermal solar devices, reducing both environmental impact and costs.

Mercatelli et al. [14] carried out an investigation to study the scattering and absorption properties of carbon nanohornbased nanofluids consisting in aqueous suspensions of single wall carbon nanohorns for solar energy applications. In order to use them as direct sunlight absorber fluids in solar devices the characteristics of these nanofluids were assessed. The investigation was carried out for nanohorns of different morphologies (dahlia-like, bud-like and seeds-like) and for suspensions prepared with different amounts of surfactant, hence measurements of extinction and absorption coefficients on Single Wall Carbon Nanohorn (SWCNH) suspensions as a function of the nanoparticle morphology was done. The differences in optical properties induced by carbon nanoparticles compared to those of pure water lead to a considerably higher sunlight absorption with respect to the pure base fluid. Scattering results indicating that the portion of light scattered by SWCNH suspensions was smaller than 5\%. This means that approximately up to $95 \%$ of light was directly absorbed. Therefore, nanohorns suspensions behave as perfect absorbers for NIR wavelengths $(833 \mathrm{~nm})$ or for longer wavelengths. Finally it was concluded that for new-generation solar collectors SWCNHs seems to be very promising as inventive direct sunlight absorbers in the field of Solar Energy. 
Han et al. [15] carried out an experimental investigation about the thermal properties of carbon black aqueous nanofluids for solar absorption. In this paper carbon black nanofluids were prepared by dispersing the pre-treated carbon black powder into distilled water. During investigation optical properties of carbon black powder and nanofluids, photo thermal properties, rheological behaviours, thermal conductivity of carbon black nanofluids were measured. The volume concentration of nanofluids taken as $4.4 \%, 5.5 \%, 6.6 \%, 7.7 \%$ and wavelength ranges from $200-2500 \mathrm{~nm}$. It was found that with high-volume fraction the nanofluids have better photo thermal properties which shows better solar energy adsorption properties. In the wavelength range from 200 to $2,500 \mathrm{~nm}$ both carbon black powder and nanofluids have good absorption characteristics. The results showed that the shear viscosity increases as the volume fraction increases and decreases as the temperature increases at the same shear rate and the thermal conductivity of carbon black nanofluids increases as the volume fraction and temperature increases. Finally it was concluded that, carbon black nanofluids have good absorption ability of solar energy and can effectively increase the solar absorption efficiency, hence carbon black nanofluids have high potentials for the utilization in solar application.

Yousefi et al. [16] carried out an experimental investigations to study the effects of $\mathrm{Al}_{2} \mathrm{O}_{3} /$ water nanofluid on the efficiency of a flat-plate solar collector. The effect of using water as the working fluid, $\mathrm{Al}_{2} \mathrm{O}_{3}$ nanofluid as the working fluid without surfactant and with surfactant on the efficiency of solar collector was investigated. Triton $\mathrm{X}-100$ was used as a surfactant. Two different weight fractions i.e. $0.2 \%$ and $0.4 \%$ of the nanofluid taken into account with diameter of the particles taken as $15 \mathrm{~nm}$. The effect of mass flow rate also taken into consideration. The mass flow rates were taken as 1, 2, $3 \mathrm{lit} / \mathrm{min}$. their results showed that:

1. With $0.2 \%$ weight fraction (wt.) $\mathrm{Al}_{2} \mathrm{O}_{3}$ nanofluid the efficiency of the solar collector is greater as compare with the water by $28.3 \%$.

2. The efficiency of the collector using $0.2 \%$ weight fraction $\mathrm{Al}_{2} \mathrm{O}_{3}$ nanofluid is higher as compared to $0.4 \%$ weight fraction for a wide range of the reduced temperature parameter.

3. By using Triton $\mathrm{X}-100$ as a surfactant the maximum enhanced efficiency of the collector is $15.63 \%$.

Yousefi et al. [1] carried out an examination using the same experimental setup as in their previous work (Yousefi et al., 2012a), to study the effects of water-Multi wall carbon nanotubes (MWCNT) $-\mathrm{H}_{2} \mathrm{O}$ nanofluid on the efficiency of the flat plate collector. The effect of using water as the working fluid, MWCNT nanofluid as the working fluid without surfactant and with surfactant on the efficiency of solar collector was investigated. Triton X-100 used as a surfactant. The authors examined the effect of two different weight fractions i.e. $0.2 \%$ and $0.4 \%$ of the nanofluid with diameter of the particles taken in the range from 10 to 30 $\mathrm{nm}$. The effect of mass flow rate also taken into account. The mass flow rates were taken as 1,2 , and 3 lit/sec. their results shows that:

1. The efficiency of the collector by using of MWCNT $-\mathrm{H}_{2} \mathrm{O}$ nanofluid as a working fluid without surfactant is remarkably increased for $0.4 \%$ weight fraction of nanofluid,

2. With $0.2 \%$ weight fraction of MWCNT nanofluid with surfactant collector 
efficiency increases and without surfactant the efficiency decreases.

3. For small values of reduced temperature differences parameter, the efficiency of collector is increased by increasing the mass flow rate. Beyond these small values, the efficiency gets a reversed trend.

Yousefi et al. [17] carried out an experimental investigation to study the effect of $\mathrm{pH}$ variation of $\mathrm{MWCNT}-\mathrm{H}_{2} \mathrm{O}$ nanofluid on the efficiency of a flat-plate solar collector. The experimental work carried out by using weight fraction of $0.2 \%$ with different $\mathrm{pH}$ values i.e. 3.5, 6.5, 9.5. Triton X-100 used as additive. The diameter of MWCNT taken as 10-30 nm. With mass flow rate of $0.0333 \mathrm{~kg} / \mathrm{s}$ the efficiency of the flat-plate solar collector with MWCNT nanofluid as a working fluid at three $\mathrm{pH}$ values $(3.5,6.5$, and 9.5.) was compared with water. It was observed that if the temperature differences higher than the mean temperature difference, the efficiency for $\mathrm{pH}=3.5$ is greater than that for $\mathrm{pH}=$ 9.5. On the other hand, if the temperature differences lower than the mean temperature difference, the efficiency of the flat-plate solar collector for $\mathrm{pH}=9.5$ is greater than that for $\mathrm{pH}=3.5$. It was also observed that, the absorbed energy parameter for $\mathrm{pH}=9.5$ is higher than that of $\mathrm{pH}=3.5$ and 6.5. Similarly, the removed energy parameter for $\mathrm{pH}=6.5$ was higher than $\mathrm{pH}=9.5$ and $\mathrm{pH}=3.5$. Among these values $\mathrm{pH}$ values removed energy parameter of $\mathrm{pH}=3.5$ was lower. From the experimental results it was concluded that, more differences between the $\mathrm{pH}$ of nanofluid and $\mathrm{pH}$ of isoelectric point leads to more improvement in the collector efficiency as the $\mathrm{pH}$ of the isoelectric point is 7.4 for MWCNT.
Saidur et al. [18] carried out an experimental investigation to study the effect of using nanofluid as working fluid for direct solar collector. The objective of this study was:

(1) To investigate the appropriateness of nanofluid as a volumetric absorber.

(2) To discover the radioactive properties of the base fluid and the nanoparticle.

(3) To determine the effect of nanoparticle sizes and volume fractions for nanofluid as well as comparing its transmissivity of light. The extinction coefficient of aluminum (Al) nanoparticle suspended in water as a base fluid was investigated and evaluated by changing nanoparticle size and volume fraction. It was seen that the nanoparticle size has negligible impact on the optical properties of nanofluid. On the other hand, the extinction coefficient of water based aluminium nanofluid is linearly proportional to volume fraction.

The authors observed that direct solar collector is expected to provide excellent optical properties and improved thermal transfer by utilizing nanofluids as a volumetric absorber. At shorter wavelength aluminum nanoparticle shows very strong extinction coefficient and peak at a wavelength of $0.3 \mu \mathrm{m}$. In spite of a lower extinction coefficient at longer wavelength, aluminium nanoparticle can be utilized to improve the light absorption ability of water at the visible and shorter wavelength region. It was observed that the improvement is promising within $1.0 \%$ volume fraction and is showing suitable enhancement to solar absorption, aluminium nanofluid is seems to be good solution for direct solar collector as a volumetric absorber.

Khullar et al. [19] studied the environmental impact of nanofluid based concentrating solar water heating system. 
This paper examines the potential of the nanofluid-based concentrating solar water heating system (NCSWHS) as a substitute to systems based on fossil fuels. Therefore, to save fossil fuels which are presently being widely used for water heating purposes the concept of NCSWHS and its potential was examined. It was found that the proposed water heating system has relatively better performance characteristics in comparison with the conventional flat plate collectors. The NCSWHS system also seems to be the best solution for fuel savings and it also promises the reduction of $\mathrm{CO}_{2}$ emission so far as it substitutes for fossil fuel water heaters. It was seen that:-

1. The common water heating system of concentrating type would be more efficient and cost effective than flat plate collector.

2. The main advantage of NCSWHS is that it is being energy efficient.

3. Higher output temperatures can be attained by using NCSWHS hence it significantly reduces greenhouse gas emissions and save enormous amount of fossil fuels.

Khullar et al. [20] carried out theoretical investigations to study a nanofluid-based concentrating parabolic solar collector (NCPSC) and the results obtained were compared with the experimental results of conventional concentrating parabolic solar collectors operating under same conditions. Aluminium nanoparticle with 0.05 vol. \% suspended in Therminol-VP-1 as the base fluid was used for the analysis. The results showed that the thermal efficiency of NCPSC compared to a conventional parabolic solar collector is about $5-10 \%$ higher under the similar weather conditions. The theoretical results indicated that the nanofluid-based concentrating parabolic solar collector has the potential to harness solar energy in a more efficient manner as compared to a conventional parabolic trough. It was observed that in order to get the desired output in terms of thermal efficiency and maximum outlet fluid temperatures, nanoparticle shape, size, and material need to be optimized and to transform this new concept of harvesting solar radiant energy into a commercial reality mathematical analysis needs to be validated with experimentation.

Chougule et al. [21] carried out an experimental investigation to check the performance of nanofluid charged solar water heater using solar tracking system. In this investigation two identical flat plate collectors using heat pipes were fabricated. The nanoparticles used in the present study are CNT having diameter 10-12 $\mathrm{nm}$ and for the preparation of nanofluid the concentration of nanoparticles taken as $0.15 \%$ by volume. Experimentations were carried in two steps i.e. by changing the collector's angle from Indian Standard i.e. normal angle $31^{\circ}$ to maximum performance angle of solar collector $50^{\circ}$ with fixed position and other step is keeping the collectors on tracking mechanism. The effect of tilt angle, Solar Tracking System, $\&$ effect on average efficiency and on heat loss factor $\left[T_{m}-T_{a} / I_{t}\right]$ was observed.

After the observation of CNTs nanofluid used as working fluid it was concluded that a very low quantity of nanoparticles results in a better performance and has remarkable potential as working fluid in high performance thermosyphon heat pipe collectors. It was also concluded that at $50^{\circ}$ tilt angle working fluids gave better performance as compared to standard normal angle in both conditions (fixed and tracking) \& average efficiencies are 
increased $12 \%$ and $11 \%$ for water and nano working fluid at $31.50^{\circ}$ tilt angle while $7 \%$ and $4 \%$ respectively at $50^{\circ}$ tilt angle using tracking system, hence Solar tracking system adds an advantage to improve the efficiency in both water as well as nano working fluid solar heat pipe collector and also each of tilt angle for solar heat pipe collector.

De Risi et al. [22] mathematically done the modelling and optimization of transparent parabolic trough collector based on gasphase nanofluids as a working fluids. To directly absorb the solar energy a new concept of solar Transparent Parabolic trough Collector (TPTC) working with gasbased nanofluid as heat transfer fluid was suggested and examined. The model of the geometrical, thermal and fluid dynamic aspects of the TPTC was developed mathematically in order to attain global performance and to describe the main geometrical and operational criterion of the TPTC. In inclusion, to optimize the performance of the solar collector a genetic algorithm optimization was used.

Numerical results revealed that the gasbased nanofluids when combine with Transparent Parabolic trough Collector can be an effective substitute to conventional systems such as synthetic oils or molten salts. Simulation of the gas based nanofluids absorption showed that a complete absorption of the solar spectrum within the diameter of the receiver tube is attained by a correct composition $(0.25 \% \mathrm{CuO}$ and $0.05 \%$ $\mathrm{Ni})$. The results also indicated that the maximum TPTC solar to thermal efficiency is $62.5 \%$.for a nanofluid outlet temperature of $650^{\circ} \mathrm{C}$ and a nanoparticles volume concentration of $0.3 \%$.
Chaji et al. [23] carried out an experimental investigation to check the Thermal Efficiency of Flat Plate Solar Collector (FPSC) using $\mathrm{TiO}_{2} /$ Water nanofluid. In this investigation to study the effects of different nanoparticle concentrations of $\mathrm{TiO}_{2}$ in water as base fluid a small flat plate solar collector (FPSC) was fabricated and tested, hence the effect of nanofluid on solar collector efficiency was evaluated for different mass flow rates $\left(36,72\right.$ and $108 \mathrm{lit} / \mathrm{m}^{2}$.hr). Three levels of $\mathrm{TiO}_{2}$ nano particles concentrations i.e. $0.1 \%, 0.2 \%, 0.3 \%$ (without using surfactants) were examined and the results were compared with those of water. It was concluded that the increase of mass flow rates of base fluid inside the solar collector enlarged the index of total collector efficiency area under the curves up to $15.7 \%$. Also, adding the nano particles to water improved the index of collector efficiency -area under the curve - between 2.6 and $7 \%$ relative to base fluid at the same flow rate.

Tiwari et al. [24] presents a comprehensive overview on thermal performance and environmental impact analysis of solar flat plate collector for water heating using $\mathrm{Al}_{2} \mathrm{O}_{3}$ water based nanofluid. The effect of utilizing the $\mathrm{Al}_{2} \mathrm{O}_{3}$ nanofluid as absorbing medium in a flat-plate solar collector was studied. The effect of mass flow rate and particle volume fraction on the efficiency of collector was also investigated. The mass flow rate taken as $30,60,90$, and 120 in lit/hr and the volume concentration taken as $0.5,1.0,1.5$, and 2.0 in percent were taken into account. It was concluded that using the $1.5 \%$ optimal particle volume fraction of $\mathrm{Al}_{2} \mathrm{O}_{3}$ nanofluid increase the thermal efficiency in comparison with water as working fluid by $31.64 \%$. 
Maddah et al. [25] carried out an experimental investigation to study the effect of silver and aluminium oxide nanoparticles on thermo physical properties of nanofluids. Thermal conductivity, electrical conductivity, and viscosity are the thermo physical properties of nanofluids. For investigation the nominal diameters of $\mathrm{Al}_{2} \mathrm{O}_{3}$ and $\mathrm{Ag}$ nanoparticles taken as 40 and $20 \mathrm{~nm}$. Nanofluids of various volume concentrations $0.25 \%$ to $5 \%$ taken into consideration at a temperature of $15^{\circ} \mathrm{C}$. The nanofluid was prepared by dispersing aluminium oxide and silver nanoparticles in distilled water and then sonication process was done. It was concluded that

1. The viscosity and thermal conductivity of nanofluids increases as volume fraction of nanoparticles increases.

2. The electrical conductivity of nanofluids increases linearly with an increase in the volume fraction of the aluminium oxide and silver nanoparticles.

It was observed that higher the concentration of nanofluids, higher is the viscosity. On the other hand, electrical conductivity of aluminium oxide and silver nanofluid is significantly greater than that of the base fluid.

\section{FUTURE WORK}

Use of nanofluids in solar energy is still an inventive idea. Based on our survey these proposals will be helpful for the development and use of nanofluids in the solar thermal devices.

\subsection{Parabolic trough systems [4]}

Only a literature work has been done on parabolic trough collectors using FDM technique, hence some experimental studies should perform to check the effects of nanofluids on the performance this system

\subsection{Solar thermoelectric cells}

Recently the evolvement of solar thermoelectric systems comes into existence. The thermoelectric cells can be used to transform the solar energy to electricity due to the temperature difference between two hot and cold surfaces. A greater temperature difference between the hot and cold surfaces of the thermoelectric cell leads to a bigger electricity production. Experimental setup to investigate the effects of nanofluids on the performance of such systems is suggested [4]. Authors suggested a construction in which a dish concentrates the solar radiation on the thermoelectric cells installed on the focal point of the dish. In this way the effects of different nanofluids with various mass flow rates on the efficiency of the solar thermoelectric cell can be studied [4].

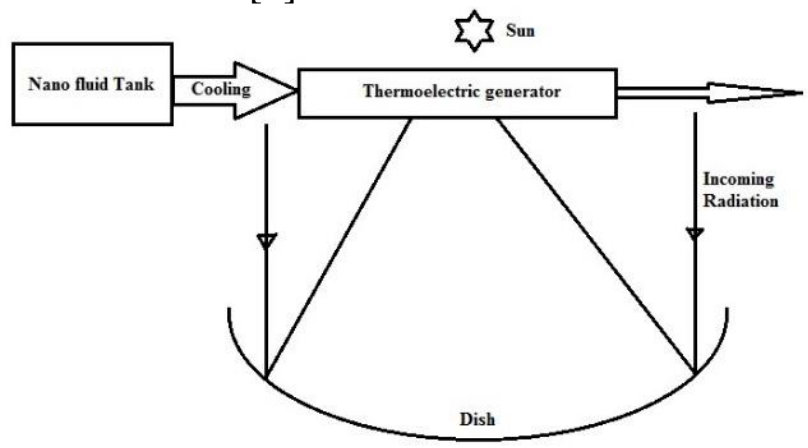

Fig.7 The experimental set-up proposed for using nanofluids in thermoelectric cells [4]

\section{CHALLENGES}

Following parameters are the possible challenges in the application of nanofluids in solar thermal systems. 


\section{High cost}

Solar thermal devices have high cost of nanofluids because of difficulties in production.

2. Instability and agglomerating Instability and agglomeration of the nanoparticles is also a big problem. Hence, nanofluids should not be used with natural circulation (such as thermosiphons) where there is no pump to circulate the fluid, in solar systems with. It should be also noted that for high temperature gradients the agglomeration of nanoparticles seems to be more serious [26]. Therefore, exact investigations are needed for an appropriate selection of a nanofluid for applications in high temperatures [4].

\section{Pumping power and pressure drop}

Using a nanofluid with higher viscosity compared to the base fluid leads to the increase of pressure drop and consequently the increases in the required power for pumping. For example, Researchers found during their experiments that the pressure drop under a turbulent regime increases with an increase in volume fraction of $\mathrm{TiO} 2 /$ water nanofluid.

\section{Erosion and corrosion of components}

Existing of nanoparticles in nanofluid may lead to corrosion and erosion of thermal devices in a long time[4]. Researchers recently investigated the effects of nanofluid flow effects on erosion and corrosion of metal surfaces. They conducted their experiments for $\mathrm{TiO}_{2}, \mathrm{Al} 2 \mathrm{O} 3, \mathrm{SiC}, \mathrm{ZrO}_{2}$ nanoparticles with water as the base fluid where the nanofluids flow in pipes with three different materials, i.e., aluminum, copper and stainless. They concluded that the nanofluids have no effect on the erosion of the stainless pipe, while the aluminum pipe has highest erosion. They also found that $\mathrm{ZrO}_{2}$ and $\mathrm{TiO}_{2}$ nanoparticles lead to highest erosion while $\mathrm{SiC}$ nanoparticles results in lowest erosion.

\section{CONCLUSION}

Nanofluids are foremost fluids containing nano-sized particles and have been used to enhance system performance in many thermal engineering systems. This paper conferred a review Performance of the Nanofluid Based Concentrated Solar Collector - Solar Energy. The experimental and numerical studies for solar collectors showed that in some cases, the efficiency could increase remarkably by using nanofluids. It was found that using a nanofluid with higher volume fraction always is not the best option. Hence, it is suggested that the nanofluids in different volume fractions should be examined to find the optimum volume fraction. It is also seen that the available literature works give different results on the effects of particle size on the efficiency of the collectors. It will be valuable to carry out an experimental work on the effect of particle size on the collector efficiency. Modelling and optimization of transparent parabolic trough collector based on gas-phase nanofluids was also carried out and the numerical results have shown that gas-based nanofluids combined with TPTC can be an effective alternative to conventional systems such as synthetic oils or molten salts that have shown different application problems in existing plants. Simulations results also show that that the maximum TPTC solar to thermal efficiency is $62.5 \%$, for a nanofluid outlet temperature of $650{ }^{\circ} \mathrm{C}$ and a nanoparticles volume concentration of $0.3 \%$.There are many proposals are conferred to develop the use of nanofluids in 
different solar systems such as parabolic trough systems, solar thermoelectric cells, etc. The critical challenges on the use of nanofluids in solar systems arrangements consist of high costs of production, agglomeration problems, instability, increased pumping power and erosion are mentioned. Such type of issues would be reduced with the development of nanotechnology in the future.

\section{REFERENCES}

1. Yousefi T., Veisy F., Shojaeizadeh E., Zinadini S., (2012b), An experimental investigation onthe effect of MWCNT-H2O nanofluid on the efficiency of flat plate solar collectors, "Experimental Thermal and Fluid Science",vol. 39, pp. 207212.

2. Saidur R., Meng T.C., Said Z., Hasanuzzaman M., Kamyar A., (2012), Evaluation of the effect of nanofluid-based absorbers on direct solar collector, "International Journal of Heat and Mass Transfer", vol. 55, issues 21-22,pp. 5899-5907.

3. Taylor R.A., Phelan P.E., Otanicar T.P., Walker C.A., Nguyen M., Trimble S., and Prasher R., (2011a), Applicability of nanofluids in high flux solar collectors, "Journal of Renewable and Sustainable Energy", vol. 3, issue 2, pp. 023104-1 to 15 .

4. Mahian O., Kianifar A. , Kalogirou S. A., Pop I. , Wongwises S., (2013), A review of the applications of nanofluids in solar energy, "International Journal of Heat and Mass Transfer", vol. 57, Issue 2, pp. 582-594.

5. Yousefi T., Veisy F., Shojaeizadeh E., Zinadini S., (2012a), An experimental investigation on the effect of Al2O3-H2O nanofluid on the efficiency of flat-plate solar collectors, "Renewable Energy", vol. 39, pp. 293-298.

6. Tyagi H., Phelan P., Prasher R., (2009), Predicted efficiency of a low-temperature nanofluid - based direct absorption solar collector, "Journal of Solar Energy Engineering”, vol. 131, pp. 0410041 to 7.

7. Otanicar T.P., Phelan P.E., Prasher R.S., Rosengarten G., and Taylor R.A., (2010), Nanofluid based direct absorption solar collector, "Journal of Renewable and Sustainable Energy", vol. 2, issue 3,pp. 0331021 to 13 .

8. Taylor R.A., Phelan P.E., Otanicar T.P., Walker C.A., Nguyen M., Trimble S., and Prasher R., (2011a), Applicability of nanofluids in high flux solar collectors, "Journal of Renewable and Sustainable Energy", vol. 3, issue 2, pp. 023104-1 to 15 .

9. Taylor R.A., Phelan P.E., Otanicar T.P., Adrian R., Prasher R.P., (2011b), Nanofluid optical property characterization: towards efficient direct absorption solar collectors, "Nanoscale Research Letters", vol. 6, issue 1, pp. 225.

10. Natarajan E. \& Sathish R., (2009), Role of nanofluids in solar water heater, "Int J Adv Manuf. Technol.", special issue, doi 10.1007/s00170008-1876-8.

11. Khullar V., Tyagi H.,(2010), Application of nanofluids as the working fluid in concentratingparabolic solar collectors, "37th National \& 4th International Conference on Fluid Mechanics \& Fluid Power", IIT 
Madras, Chennai, India, Dec. 16-18, Paper No. FMFP2010-179.

12. Sani E., Barison S., Pagura C., Mercatelli L., Sansoni P., Fontani D., Jafrancesco D. and Francini F., (2010), Carbon nanohorns-based nanofluids as direct sunlight absorbers, "journal optic express", vol. 18, issue. 5, pp.1-9.

13. Sani E., Mercatelli L., Barison S, Pagura C. , Agresti F., Colla L., Sansoni P.,(2011), Potential of carbon nanohorn-based suspensions for solar thermal collectors, "Solar Energy Materials \& Solar Cells", vol. 95, Issue 11, pp. 2994-3000.

14. Mercatelli L., Sani E., Fontani D., Zaccanti G., Martelli F., Di Ninni P.,(2011), Scattering andabsorption properties of carbon nanohorn-based nanofluids for solar energy applications, "Journal of the European Optical Society-Rapid Publications", vol. 6, pp.11025-1 to 5.

15. Han D., Meng Z., Wu D., Zhang C., Zhu H.,(2011), Thermal properties of carbon black aqueous nanofluids for solar absorption, "Nanoscale Research Letters",vol. 6,pp.1-7.

16. Yousefi T., Veisy F., Shojaeizadeh E., Zinadini S., (2012a), An experimental investigation onthe effect of A12O3-H2O nanofluid on the efficiency of flat-plate solar collectors, "Renewable Energy",vol. 39, pp. 293-298.

17. Yousefi T., Shojaeizadeh E., Veysi F., Zinadini S., (2012c), An experimental investigation on the effect of $\mathrm{pH}$ variation of MWCNT$\mathrm{H} 2 \mathrm{O}$ nanofluid on the efficiency of a flat-plate solar collector, "Solar
Energy”, vol. 86, Issue 2, pp. 771779.

18. Saidur R., Meng T.C., Said Z., Hasanuzzaman M., Kamyar A., (2012), Evaluation of the effect of nanofluid-based absorbers on direct solar collector, "International Journal of Heat and Mass Transfer", vol. 55, issues 21-22,pp. 5899-5907.

19. Khullar V., Tyagi H., (2012a), A study on environmental impact of nanofluid based concentrating solar water heating system, "International Journal of Environmental Studies”, vol. 69, issue 2, pp. 220-232.

20. Khullar V., Tyagi H., Phelan P.E., Otanicar T.P., Singh H., Taylor R.A.,(2012b), Solar energy harvesting using nanofluids-based concentrating solar collector, "Journal of Nanotechnology in Engineering and Medicine”, vol. 3 ,pp. 031003-1 to 9.

21. Chougule Sandesh S., Pise Ashok T., Madane Pravin A.,(2012), Performance of nanofluid charged solar water heater by solar tracking system, In: Proceedings of "IEEEInternational Conference On Advances In Engineering, Science And Management (ICAESM -2012)" March 30, 31,2012,pp.247-253.

22. De Risi A., Milanese M., Laforgia D.,(2013), Modelling and optimization of transparent parabolic trough collector based on gas-phase nanofluids,

"Renewable Energy",vol. 58,pp.134-139.

23. Chaji H., Ajabshirchi Y., Esmaeilzadeh E., Heris Saeid Z., Hedayatizadeh M. , Kahani M., (2013), Experimental study on thermal efficiency of flat plate solar collector using $\mathrm{TiO} 2 /$ Water 
nanofluid, "Modern Applied Science" published by Canadian Centre of Science and Education, vol. 7, issue 10,pp.60-69.

24. Tiwari A. K., Ghosh P., Sarkar J., (2013), Solar water heating using nanofluids-a comprehensive overview and environmental impact analysis, "International Journal of Emerging Technology and Advanced Engineering", vol. 3, Issue 3:ICERTSD 2013, pp. 221-224.

25. Maddah H., Rezazadeh M., Maghsoudi M., NasiriKokhdan S., (2013), The effect of silver and aluminium oxide nanoparticles on thermophysical properties of nanofluids, "Journal of Nanostructure in Chemistry", vol. 3, pp.1-6.

26. Taylor R.A., Phelan P.E., Adrian R.J., Gunawan A., Otanicar T.P.,(2012), Characterization of lightinduced, volumetric steam generation in nanofluids, "International Journal of Thermal Sciences", vol.56,pp. 1-11. 